\title{
Effectiveness of Trainings Based on the Theory of Reasoned Action in the Choice of Natural Delivery by Pregnant Women
}

\author{
Saiideh Norouzi ${ }^{1}$, Fatemeh Moghaddam ${ }^{1 *}$, Fariba Sharafi ${ }^{1}$
}

\begin{abstract}
Objectives: Due to the high rate of caesarian-section (C-section) in Iran, the aim of this research was to design and implement interventions based on the theory of reasoned action in pregnant women to promote the choice of natural delivery.

Materials and Methods: This quasi-experimental intervention was performed in Abhar, Iran on 200 pregnant women in the two groups of intervention and control. Data were collected, using a questionnaire designed by the researcher, before and after the intervention. Validity and reliability of the questionnaire were confirmed. The single-stage random cluster sampling was used. Data were analyzed using IBM SPSS Statistics 23 and statistical tests such as analysis of variance (ANOVA), Pearson correlation coefficient, $t$ test, regression, and logistic regression.

Results: Paired $t$ test showed a significant difference in the mean scores of constructs of theory of reasoned action before and after training in the intervention group; however, no statistically significant difference was observed in the control group in terms of mean scores of constructs of theory of reasoned action. Logistic regression showed that, before training, none of the reasoned action constructs predicted natural delivery in the intervention group; however, in the intervention group after training, normative beliefs, motivations to comply and behavioral intention predicted natural delivery. The same test showed that only motivations to comply predicted natural delivery in the control group before and after training.

Conclusions: It can be concluded that the theory of reasoned action can be effective in creating and enhancing pregnant women's choice of natural delivery. Therefore, considering that rate of C-section is increasing in Iran, this theory can be a useful tool for designing and implementing educational interventions aimed at improving the choice of natural delivery by pregnant women. Keywords: Theory of reasoned action, Labor, Women, Education
\end{abstract}

\section{Introduction}

The prevalence of caesarian-section (C-section) has been increasing worldwide, and Iran has not been the exception (1). However, C-section is regarded as a major surgery and, similar to other major surgical procedures, is associated with side effects that sometimes can be very dangerous and rarely fatal (2). The complications of C-section are much more serious than those of normal delivery. Some of these complications include uterine infection, fever, severe wound infection and abdominal wall apoptosis, abdominal infection, bleeding, anesthesia complications, urinary tract injury during $\mathrm{C}$-section delivery, blood clots in legs, increased maternal mortality, as well as higher costs than natural delivery $(3,4)$. According to statistics, C-section deliveries account for $25.7 \%$ of all deliveries, which varies form 3.2\% in Angola and 46.2\% in China. The study conducted in 23 countries reported the rate of C-section for non-medical reasons between $0.01 \%$ to $2.1 \%$ (5), while according to statistics released by the World Health Organization (WHO), the rate of C-section in Iran is $41.9 \%, 6 \%$ of which are considered unnecessary surgical procedures (6).

Factors affecting C-section are very complex, and it is very challenging to address them while evaluating the effectiveness of interventions to reduce the choice of C-section. Decisions regarding C-section are made by the mother and the physician and are influenced by a range of external factors. These decisions can be made during pregnancy and even before labor and can be due to medical (for mother and baby) or psychosocial reasons (7). Qualitative studies have shown that pregnant women's improper attitudes, perceived behavioral control, and poor subjective norms during the third trimester of pregnancy are the factors that influence the choice of C-section $(8,9)$. Addressing the factors that affect mothers' choice and decision regarding the type of delivery seems essential. Various studies have emphasized teaching the skills necessary for pregnant women and their partners to choose a suitable delivery method (8-10).

Therefore, guidance and training for pregnant women can reduce the rate of unnecessary $\mathrm{C}$-section deliveries, enabling mothers to acquire the necessary knowledge to 
choose the appropriate method with the help of doctors and not to undergo unnecessary C-sections (11). On the other hand, theories play a major role in health education, enabling health care workers to have specific and appropriate choices for each situation (12). Studies show that a behavioral intention model can be used in relation with fertility behavioral attitudes (13). This model is based on a psychological theory known as the theory of reasoned action. An important feature of this theory is that the behavioral intention is the most important determinant of behavior and is examined by the individual before deciding to engage in any behavior. This theory includes the following constructs:

- Behavior: The way a person acts, the conduct and attitude and reaction under various circumstances,

- Behavioral intention: The person's decision to adopt a behavior,

- Attitude toward behavior: Desirability of a behavior,

- Subjective norms: Different people that affect the individual,

- Perceived behavioral control: The feeling of how much doing or not doing a behavior is under the individual's voluntary control (14).

A quasi-experimental intervention was conducted by Khan-Jeihooni et al, where data were collected using questionnaires. After the pre-test, specific training was provided based on the theory of reasoned action. Posttest was conducted in both groups 3 months after the training. It was concluded that the intervention effectively increased pregnant women's knowledge and promoted their evaluation of outcomes, and behavioral beliefs and strengthened their intention and performance. It was suggested that this model and systematic training framework are used for pregnant women to reduce the C-section rate (15). Another study showed that the theory of reasoned action can be effective in creating and enhancing pregnant women's choice of natural delivery. Further research on the factors related to the choice of delivery method, especially from intention to conducting the behavior was recommended (16).

Another study showed that training using the theory of planned behavior had a significant effect on the increased choice of natural delivery in the studied population. Therefore, considering the effect of trainings based on this theory, it was recommended that pregnant women with elective C-section receive educational packages based on this theory and participate in group discussions. Accordingly, the aim of this project was to use the theory of reasoned action in the choice of natural delivery by pregnant women who visited health centers is Abhar, Iran.

\section{Materials and Methods}

This semi-experimental interventional study was conducted on 200 pregnant women who visited health centers in Abhar, Iran. Inclusion and exclusion criteria were: pregnant women in the second trimester of pregnancy who had completed the consent form, pregnant women in the second and third trimester of pregnancy with no indication for C-section, pregnant women who wished not to continue participating in the study, and exclusion criteria included pregnant women who had planned to have a normal delivery from the beginning of the study, and mothers with a necessary $\mathrm{C}$-section. The study population included all pregnant women in the second and third trimesters of pregnancy who visited health centers in Abhar (17 Shahrivar Health Center, Shenat 22 Bahman Health Center, and Shenat Health Center). First, from the health centers in Abhar, 4 health centers were selected using the single-stage random cluster method. The 17 Shahrivar Health Center and its clinics were considered as the intervention group, while the 22 Bahman Health Centers and its clinics were considered as the control group. Sample size was 200, which was calculated based on the number of pregnant women who visited the health centers (17 Shahrivar health center, Shenat 22 Bahman health center, and Shenat health center) to receive midwifery services. The participants were first informed of the nature of research, and its objectives, and benefits. Written consents were obtained. The questionnaires were then distributed among pregnant women and were then collected. The educational classes, which were based on the theory of reasoned action, were conducted for 3 months for the intervention group for a total of 12 sessions (one meeting each week). A midwife, a health education specialist, and a gynecologist managed the classes. A post-test was conducted to determine the effects of intervention in changing their opinion in the choice of normal delivery in both groups. Due to time constraints, the post-test was conducted one month after the intervention. In order to determine the impact of interventions on behaviors (i.e., normal delivery), followups were performed for mothers in both groups by phone or after their visit to the health center to receive services.

Data collecting tool was a researcher-designed questionnaire whose validity and reliability were measured in a pilot study. Content and face validity of the questionnaire were assessed by experts, and its construct validity was assessed by exploratory and confirmatory factor analysis. Its reliability was calculated as $89 \%$ using Cronbach $\alpha$.

The questionnaire consisted of demographic data and 6 constructs of theory of reasoned action. The first construct was behavioral beliefs, which contained 17 items. The second construct was evaluation of outcomes, which contained 17 items. The third construct was normative beliefs, which contained 5 items. The fourth construct was motivation to comply, which contained 5 items. The fifth construct was behavioral intention, which contained 3 items. The sixth construct was behavior, which contained 1 item. All items were measured using a Likert scale.

Statistical tests, such as analysis of variance (ANOVA), Pearson correlation coefficient, $t$ test, regression, and 
logistic regression, were performed using IBM SPSS version 23.

Ethical considerations included obtaining consent from participants and obtaining permission from the university. Measures were also taken to provide training for the control group after the intervention. The possibility of pregnant mothers not cooperating was a limitation that was prevented by incentives (cash and non-cash prizes), making classes more interesting, and engaging the mothers in the issue.

\section{Results}

Demographic characteristics of subjects are shown in Tables 1 and 2.

Table 3 shows mean and standard deviation of the scores of the constructs of theory of reasoned action in the intervention and control groups before and after the intervention.

Table 1. Mean, Standard Deviation, and Minimum and Maximum Levels of Some Demographic Variables

\begin{tabular}{lcc}
\hline Demographic Variables & Mean \pm SD & Minimum-Maximum \\
\hline Mother's age & $28.14 \pm 5.90$ & $15-40$ \\
Husband's age & $32.36 \pm 6.82$ & $20-66$ \\
Gestational age (wk) & $26.90 \pm 7.61$ & $6-40$ \\
Income (Tomans) & $1400000 \pm 250000$ & $0-2000000$ \\
\hline
\end{tabular}

Table 2. Frequency and Percentage of Demographic Variables

\begin{tabular}{lllc}
\hline Demographic Variables & & No. & Percent \\
\hline Woman's occupation & Housewife & 180 & 90 \\
& Employed & 20 & 10 \\
Husband's occupation & Worker & 75 & 37.5 \\
& Employee & 31 & 15.5 \\
& Self-employed & 82 & 41 \\
Women's education level & Middle school & 39 & 19.5 \\
& High school & 84 & 42 \\
Husband's education level & College & 63 & 31.5 \\
& Middle school & 49 & 24.5 \\
& High school & 99 & 49.5 \\
Insurance & College & 40 & 20 \\
& Social security & 116 & 58 \\
Number of children & Health service & 33 & 16.5 \\
& No children & 104 & 52 \\
Type of previous deliveries & One child & 78 & 39 \\
& Natural & 114 & 57 \\
& C-section & 86 & 39 \\
\hline
\end{tabular}

Table 4 compares mean scores of the constructs of theory of reasoned action in the intervention and control groups before and after the intervention.

Paired $t$ test showed a significant difference between mean scores of constructs of theory of reasoned action before and after training in the intervention group $(P=0.00)$; however, no statistically significant difference was found between mean scores of constructs of theory of reasoned action before and after training in the control group $(P \geq 0.05)$.

Logistic regression showed that, in the intervention group before training, none of the constructs of behavior model predicted the choice of natural delivery; however, after training, normative beliefs $(B=0.07$ and $P=0.02)$, motivation to comply $(\mathrm{B}=0.06$ and $P=0.02)$, and behavioral intention $(\mathrm{B}=0.06$ and $P=0.05)$ predicted the choice of natural delivery in the intervention group.

This test showed that, before and after training, only motivation for comply $(\mathrm{B}=0.06$ and $P=0.02)$ predicted the choice of natural delivery in the control group.

Tables 5 and 6 show the correlation between the constructs of theory of reasoned action before and after the intervention.

ANOVA results showed that the only significant difference was observed between the income and choice of normal delivery $(P=0.003)$.

\section{Discussion and Conclusions}

Findings showed that, in the intervention group before training, none of the constructs of the model predicted the choice of normal delivery; however, after training, normative beliefs, motivation to comply, and behavioral intention predicted the choice of normal delivery in the intervention group. The tests showed that, before and after training, only motivation to comply predicted the choice of normal delivery in the control group. Paired $t$ test showed a significant difference between the mean scores of constructs of theory of reasoned action before and after training in the intervention group. Findings generally were indicative of the effect of training interventions. Shahraki Sanavi et al conducted a quasi-experimental study on 200 pregnant women in their third trimester of pregnancy with the intention or the decision to have elective C-section using the non-probability sampling technique. Their findings showed that the training based on the theory of planned behavior had a significant impact

Table 3. Mean and Standard Deviation of the Scores of the Constructs of Theory of Reasoned Action Before and After the Intervention in the Intervention and Control Groups

\begin{tabular}{|c|c|c|c|c|c|c|}
\hline & $\begin{array}{l}\text { Behavioral } \\
\text { Beliefs }\end{array}$ & $\begin{array}{l}\text { Evaluation of } \\
\text { Outcomes }\end{array}$ & $\begin{array}{l}\text { Normative } \\
\text { Beliefs }\end{array}$ & $\begin{array}{l}\text { Motivation } \\
\text { to Comply }\end{array}$ & $\begin{array}{l}\text { Behavioral } \\
\text { Intention }\end{array}$ & Behavior \\
\hline Intervention group before training & $25.34 \pm 5.51$ & $20.49 \pm 3.52$ & $6.58 \pm 1.57$ & $5.83 \pm 1.70$ & $5.30 \pm 2.51$ & $1.28 \pm 0.45$ \\
\hline Intervention group after training & $3.16 \pm 9.93$ & $22.59 \pm 5.69$ & $12.91 \pm 5.48$ & $8.83 \pm 3.38$ & $5.81 \pm 3.36$ & $1.59 \pm 0.49$ \\
\hline Control group before training & $29.72 \pm 9.75$ & $22.63 \pm 5.73$ & $12.91 \pm 5.48$ & $8.78 \pm 3.35$ & $5.79 \pm 3.34$ & $1.60 \pm 0.49$ \\
\hline Control group after training & $3.16 \pm 9.93$ & $22.59 \pm 5.69$ & $12.91 \pm 5.48$ & $8.83 \pm 3.38$ & $5.81 \pm 3.36$ & $1.55 \pm 0.5$ \\
\hline
\end{tabular}


Table 4. Comparison of Mean Scores of the Constructs of Theory of Reasoned Action in the Intervention and Control Groups Before and After the Intervention

\begin{tabular}{|c|c|c|c|c|c|c|}
\hline & $\begin{array}{l}\text { Behavioral } \\
\text { Beliefs }\end{array}$ & $\begin{array}{l}\text { Evaluation of } \\
\text { Outcomes }\end{array}$ & $\begin{array}{l}\text { Normative } \\
\text { Beliefs }\end{array}$ & $\begin{array}{l}\text { Motivation to } \\
\text { Comply }\end{array}$ & $\begin{array}{l}\text { Behavioral } \\
\text { Intention }\end{array}$ & Behavior \\
\hline Intervention group before training & $25.34 \pm 5.51$ & $20.49 \pm 3.52$ & $6.58 \pm 1.57$ & $5.83 \pm 1.70$ & $5.30 \pm 2.51$ & $1.28 \pm 0.45$ \\
\hline Intervention group after training & $3.16 \pm 9.93$ & $22.59 \pm 5.69$ & $12.91 \pm 5.48$ & $8.83 \pm 3.38$ & $5.81 \pm 3.36$ & $1.59 \pm 0.49$ \\
\hline$P$ & 0.000 & 0.001 & 0.000 & 0.000 & 0.001 & 0.000 \\
\hline Control group before training & $29.72 \pm 9.75$ & $22.63 \pm 5.73$ & $12.91 \pm 5.48$ & $8.78 \pm 3.35$ & $5.79 \pm 3.34$ & $1.60 \pm 0.49$ \\
\hline Control group after training & $3.16 \pm 9.93$ & $22.59 \pm 5.69$ & $12.91 \pm 5.48$ & $8.83 \pm 3.38$ & $5.81 \pm 3.36$ & $1.55 \pm 0.5$ \\
\hline$P$ & 0.90 & 0.92 & 1.000 & 0.87 & 0.93 & 0.77 \\
\hline
\end{tabular}

Table 5. Correlation Coefficient Between the Constructs of Theory of Reasoned Action Before and After Training in the Intervention Group

\begin{tabular}{|c|c|c|c|c|c|c|}
\hline & $\begin{array}{l}\text { Behavioral } \\
\text { Beliefs }\end{array}$ & $\begin{array}{l}\text { Evaluation of } \\
\text { Outcomes }\end{array}$ & $\begin{array}{l}\text { Normative } \\
\text { Beliefs }\end{array}$ & $\begin{array}{l}\text { Motivation to } \\
\text { Comply }\end{array}$ & $\begin{array}{l}\text { Behavioral } \\
\text { Intention }\end{array}$ & Behavior \\
\hline Behavioral beliefs & 0 & & & & & \\
\hline \multirow[t]{2}{*}{ Evaluation of outcomes } & $* * 0.51$ & 0 & & & & \\
\hline & 0.000 & & & & & \\
\hline \multirow[t]{2}{*}{ Normative beliefs } & $* * 0.39$ & $* * 0.21$ & 0 & & & \\
\hline & 0.000 & 0.005 & & & & \\
\hline \multirow[t]{2}{*}{ Motivation to comply } & $* * 0.42$ & $* * 0.36$ & $* * 0.66$ & 0 & & \\
\hline & 0.000 & 0.000 & 0.000 & & & \\
\hline \multirow[t]{2}{*}{ Behavioral intention } & $* 0.20$ & $* * 0.024$ & $* * 0.47$ & $* * 0.37$ & 0 & \\
\hline & 0.01 & 0.001 & 0.000 & 0.000 & & \\
\hline \multirow[t]{2}{*}{ Behavior } & -0.01 & 0.05 & $* 0.18$ & 0.13 & -0.07 & 0 \\
\hline & 0.89 & 0.47 & 0.01 & 0.05 & 0.31 & \\
\hline
\end{tabular}

Table 6. Correlation Coefficient Between the Constructs of Theory of Reasoned Action Before and After Training in the Control Group

\begin{tabular}{|c|c|c|c|c|c|c|}
\hline & Behavioral Beliefs & $\begin{array}{l}\text { Evaluation of } \\
\text { Outcomes }\end{array}$ & Normative Beliefs & $\begin{array}{l}\text { Motivation to } \\
\text { Comply }\end{array}$ & $\begin{array}{l}\text { Behavioral } \\
\text { Intention }\end{array}$ & Behavior \\
\hline Behavioral beliefs & 0 & & & & & \\
\hline \multirow[t]{2}{*}{ Evaluation of outcomes } & $* * 0.42$ & 0 & & & & \\
\hline & 0.000 & & & & & \\
\hline \multirow[t]{2}{*}{ Normative beliefs } & $* * 0.31$ & 0.12 & 0 & & & \\
\hline & 0.000 & 0.13 & & & & \\
\hline \multirow[t]{2}{*}{ Motivation to comply } & $* * 0.33$ & $* * 0.31$ & $* * 0.58$ & 0 & & \\
\hline & 0.000 & 0.000 & 0.000 & & & \\
\hline \multirow[t]{2}{*}{ Behavioral intention } & $* 0.20$ & $* 0.13$ & $* * 0.71$ & $* * 0.45$ & 0 & \\
\hline & 0.01 & 0.01 & 0.000 & 0.000 & & \\
\hline \multirow[t]{2}{*}{ Behavior } & 0.12 & 0.08 & 0.04 & $* 0.15$ & -0.04 & 0 \\
\hline & 0.12 & 0.28 & 0.55 & 0.04 & 0.51 & \\
\hline
\end{tabular}

on the increased choice of natural delivery in the studied population. Therefore, considering the effectiveness of trainings on the basis of this theory, it was recommended that a policy be adopted to enable pregnant women with the intention of elective $\mathrm{C}$-section receive educational packages based on this theory and attend group discussion sessions (17).

Sharghi et al conducted a cross-sectional study on 396 women in the last trimester of pregnancy who were selected through a two-step sampling method. Findings showed that social factors and motivation to comply to abstract norms, particularly from doctors and health personnel, had a significant impact on final plans for health-related behaviors. Addressing such social factors could back mothers' plan to have natural delivery and support them in the choice of natural delivery through raising awareness and improving attitudes towards natural delivery $(18,19)$.

The study by Khan-Jeihooni et al (15) was a quasiexperimental study conducted on 100 pregnant nulliparous women. Data were collected through questionnaires. After the pre-test, specific training based on the theory of reasoned action was provided, and 3 months after the training, post-test was conducted in both groups. Their findings showed that intervention effectively promoted the mothers' knowledge, evaluation of outcomes, and behavioral beliefs, and strengthened their choice and performance. Therefore, it was recommended that this model and other systematic trainings be used for pregnant women to reduce the rate of C-section (20).

In a quasi-experimental study by Asadi et al on 90 pregnant women who planned to have elective C-section, 
45 women in the intervention group received training based on the theory of reasoned action, while the other 45 in the control group received the routine intervention. The ultimate effect of the intervention was evaluated by examining the births recorded in the household records. It was concluded that the theory of reasoned action could create and enhance the choice of natural delivery in pregnant women. Further research was recommended on the factors related to the choice of delivery method, especially from the behavioral intention stage to the behavior conduction stage $(16,19)$.

Our findings were consistent with the findings of studies conducted on theory of reasoned action, all indicating the effect of application of the theory of reasoned action to increase the choice of normal delivery in pregnant women (21).

Considering that normative beliefs, motivation to comply, and behavioral intention predicted the choice of normal delivery, it can be concluded that pregnant women are influenced by these constructs and obey the constructs around them. Thus, in addition to the interventions that are designed for pregnant women, a series of interventions should aim the families (husbands, mothers, mother-inlaws, friends, etc), especially husbands, to further take the step as the final goal, which is the choice of natural delivery by the mothers (22).

Theory of reasoned action can effectively create and promote the choice of pregnant women to have natural delivery. Therefore, considering the increased rate of C-section in Iran, this theory can be a useful tool for designing and implementing educational interventions aimed at promoting the choice of normal delivery by pregnant women. In addition, use of various pain relief methods, including Lamaze, giving birth in the water, consulting, psychological and emotional support, can help take effective steps in order to increase the mothers' willingness to have vaginal delivery. Increased self-efficacy can also effectively enhance the choice of vaginal delivery.

Generally, educational interventions should be designed aimed at enhancing the choice of vaginal delivery and promoting delivery programs. Given that the interventions designed based on this theory has been proven in several studies to promote the choice of vaginal delivery, it is recommended that these types of interventions are provided in health centers by health-care providers to further move towards our goal, which is an increased rate of natural delivery and reduced rate of C-section in Iran.

\section{Conflict of Interests}

Authors declare that there is no conflict of interests.

\section{Ethical Issues}

The study was reviewed and approved by the Ethics Committees of Zanjan University of Medical Sciences (A-111048-4). The process of sampling and examination began after explaining the project to the women. Participation in the study was voluntary. Written informed consent was obtained from the women.

\section{Financial Support}

None.

\section{Acknowledgments}

The authors would like to thank Mrs. Farahnaz Hajikhani, the family health expert in Abhar Health Center, and all the staff who helped us in this project.

\section{References}

1. Tabandeh A, Kashani E. The Prevalence of Ce-Sarean among Employed Educated Women of Medical Science Groups in Gorgan (2005). J Gorgan Univ Med Sci. 2007;9(2):67-70. [Persian].

2. Krishnamoorthy U, Schram $\mathrm{CMH}$, Hill SR: Maternal obesity in pregnancy: is time for meaningful research to inform preventive and management strategies? BJOG 2006;113:1134-1140.

3. Cunningham F, Leveno K, Bloom S, Hauth JC, Rouse DJ, Spong CY. Williams Obstetrics. 23rd ed. New York: Mcgraw Hill; 2011:509-531.

4. Rezakhani Moghaddam H, Shojaeizadeh D, Taghdisi MH, Hamidzadeh Arbabi Y, Savadpour MT. The effect of education by community health volunteers on choice of delivery kind in pregnant women based on the Behavioral Intention Model (BIM). Journal of School of Public Health and Institute of Public Health Research 2013;10(3):27-40. [Persian].

5. UNDP, UNFPA, WHO. Caesarean Section Without Medical Indication Increases Risk of Short-term Adverse Outcomes for Mothers. Geneva: WHO; 2010:2.

6. Gibbons L, Belizan JM, Lauer JA, Betran AP, Merialdi M, Althabe F. The global numbers and costs of additionally needed and unnecessary caesarean sections performed per year: overuse as a barrier to universal coverage. Geneva: WHO; 2010:30.

7. Khunpradit S, Tavender E, Lumbiganon P, Laopaiboon M, Wasiak J, Gruen RL. Non-clinical interventions for reducing unnecessary caesarean section. Cochrane Database Syst Rev. 2011(6):Cd005528. doi:10.1002/14651858.CD005528. pub2

8. Yazdizadeh B, Nedjat S, Mohammad K, Rashidian A, Changizi N, Majdzadeh R. Cesarean section rate in Iran, multidimensional approaches for behavioral change of providers: a qualitative study. BMC Health Serv Res. 2011;11:159. doi:10.1186/1472-6963-11-159

9. Sanavi FS, Rakhshani F, Ansari-Moghaddam A, Edalatian M. Reasons for Elective Cesarean Section amongst Pregnant Women; A Qualitative Study. J Reprod Infertil. 2012;13(4):237-240.

10. Sharifirad G, Rezaeian M, Soltani R, Javaheri S, Mazaheri MA. A survey on the effects of husbands' education of pregnant women on knowledge, attitude, and reducing elective cesarean section. J Educ Health Promot. 2013;2:50. doi:10.4103/2277-9531.119036

11. Besharati F, Hazavehei S, Moeini B, Moghimbeigi A. Effect of Educational Interventions Based on Theory of Planned 
Behavior (TPB) in Selecting Delivery Mode among Pregnant Women Referred to Rasht Health Centers. J Zanjan Univ Med Sci. 2011;19(77):94-106. [Persian].

12. Rafee Far SH. From Health Education to Health. 1st ed. Tehran: Tandees Press; 2005:113-117. [Persian].

13. Fathian Z, Sharifirad GR, Hasanzadeh A. Study of the Effects of Behavioral Intention Model Education On Reducing the Cesarean Rate among Pregnant Women of Khomeiny- Shahr, Isfahan, In 2006. Zahedan J Res Med Sci.2007;9(2):123-131.

14. Glanz K, Rimer BK, Viswanath K. Theory, Research, and Practice. 4th ed. San Francisco: Jossey-Bass Press; 2008.

15. Khan-Jeihooni A, Shahidi F, Kashfi SM. Effectiveness of educational program based on the theory of reasoned action to decrease the rate of cesarean delivery among pregnant women in Fasa, Southern Iran. J Educ Community Health. 2014;1(1):62-71. doi:10.20286/jech-010162

16. Asadi ZS, Solhi M, Taghdisi MH, Moghadam Hoseini V, Javan R, Hashemian M. The effect of educational intervention based on Theory of Reasoned Action (TRA) on selected delivery method, for selective cesarean section in pregnant women. Iranian Journal of Obstetrics, Gynecology and Infertility. 2014;17(109):1-8. doi:10.22038/ ijogi.2014.3227

17. Shahraki Sanavi F, Navidian A, Rakhshani F, AnsariMoghaddam A. The effect of education on base the Theory of Planned Behavior toward normal delivery in pregnant women with intention elective cesarean. Med J Hormozgan Univ. 2014;17(6):531-539. [Persian].

18. Sharghi A, Kamran A, Sharifirad GR. Assessing The Factors Influencing Delivery Method Selection In Primiparous Pregnant Women Referred To Health Centers In Ardabil, 2010. Med J Hormozgan Univ. 2011;15(3):234-242. [Persian].

19. Khoursandi M, Ghofranipour FA, Heydarnia AR, Faghihzadeh S, Akbarzadeh AR, Vafaei M. Survey study of childbirth self efficacy among pregnant women. Journal of Medical Council of IRI. 2008;26(1);89-95. [Persian].

20. Sharifirad GH, Fathian Z, Tirani M, Mahaki B. Study On Behavioral Intention Model (BIM) To The Attitude Of Pregnant Women Toward Normal Delivery And Cesarean Section In Province Of Esfahan -Khomeiny Shahr-1385. J Ilam Univ Med Sci. 2007;15(1):19-23. [Persian].

21. Kanani S, Allahverdipour $H$, AsghariJafarabadi M. Modeling the intention to choose natural vaginal delivery: using reasoned action and social cognitive theories. Health Promot Perspect. 2015;5(1):24-33. doi:10.15171/ hpp.2015.004

22. Norouzi S, Motlagh Z, Masoumi N, Tavassoli E, Moghaddam F. Educational Need Assessment of Infertile Women Admitted to Yazd Reproductive Sciences Institute. Int J Womens Health Reprod Sci. 2017;5(2):123-128. doi:10.15296/ijwhr.2017.23

(c) 2018 The Author (s); This is an open-access article distributed under the terms of the Creative Commons Attribution License (http://creativecommons.org/licenses/by/4.0), which permits unrestricted use, distribution, and reproduction in any medium, provided the original work is properly cited. 